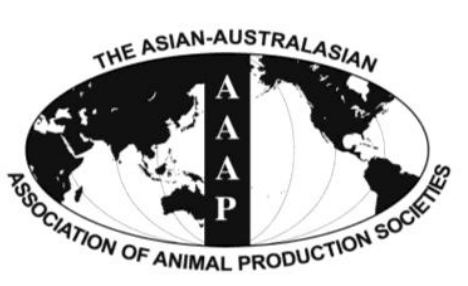

Open Access

Asian Australas. J. Anim. Sci.

Vol. 27, No. 8 : 1075-1081 August 2014

http://dx.doi.org/10.5713/ajas.2013.13587

www.ajas.info

pISSN 1011-2367 elSSN 1976-5517

\title{
Identification of SNPs in Cellular Retinol Binding Protein 1 and Cellular Retinol Binding Protein 3 Genes and Their Associations with Laying Performance Traits in Erlang Mountainous Chicken
}

\author{
Yan Wang ${ }^{\text {a }}$, Li-Hua Xiao ${ }^{\text {1,a }}$, Xiao-Ling Zhao, Yi-Ping Liu, and Qing Zhu* \\ Laboratory of Animal Genetic and Breeding, Institute of Animal Genetics and Breeding, \\ Sichuan Agricultural University, Ya'an, Sichuan, 625014, China
}

\begin{abstract}
CRBP1 (cellular retinol binding protein 1) and CRBP3 (cellular retinol binding protein 3), are important components of the retinoid signaling pathway and take part in vitamin A absorption, transport and metabolism. Based on the role of vitamin A in chicken laying performance, we investigated the polymorphism of CRBP1 and CRBP3 genes in 349 chickens using single strand conformation polymorphism and DNA sequencing methods. Only one polymorphism was identified in the third intron of $C R B P 1$, two polymorphisms were detected in CRBP3; they were located in the second intron and the third intron respectively. The association studies between these three SNPs and laying performance traits were performed in Erlang mountainous chicken. Notably, the SNP g.14604G $>\mathrm{T}$ of $C R B P 1$ was shown to be significantly associated with body weight at first egg (BWFE), age at first egg (AFE), weight at first egg (WFE) and total number of eggs with 300 age (EN). The $C R B P 3$ polymorphism g.934C $>\mathrm{G}$ was associated with AFE, and the g.1324A $>\mathrm{G}$ was associated with AFE and BWFE, but none of these polymorphisms were associated with egg quality traits. Haplotype combinations constructed on these two SNPs of CRBP3 gene were associated with BWFE and AFE. In particular, diplotype H2H2 had positive effect on AFE, BWFE, EN, and average egg-laying interval. We herein describe for the first time basic research on the polymorphism of chicken $C R B P 1$ and $C R B P 3$ genes that is predictive of genetic potential for laying performance in chicken. (Key Words: CRBP1, CRBP3, Laying Performance, Egg Quality, Gene Polymorphism, Erlang Mountainous Chicken)
\end{abstract}

\section{INTRODUCTION}

Retinoids, metabolites of vitamin A (retinol), play some essential physiological roles in both vertebrates and invertebrates through control of cell differentiation, proliferation and apoptosis (Linan-Cabello et al., 2002; Reichrath et al., 2007). Besides these functions, retinoids also affect many other vital processes including vision (Rando et al., 1994), reproduction (Eskild et al, 1994), immune function (Ross et al., 1994), growth and development (Hofmann et al., 1994) and hematopoiesis.

\footnotetext{
* Corresponding Author: Qing Zhu. Tel: +86-835-2882006, Fax: +86-835-2886080, E-mail: zhuqing5959@163.com

1 Breed Improving Station of Livestock and Poultry of Zunyi City, Guizhou, 563000, China.

${ }^{\text {a }}$ These authors contributed equally to this work.

Submitted Sept. 19, 2013; Revised Dec. 16, 2013; Accepted Jan. 16, 2014
}

Since animals cannot synthesize retinoids, vitamin $\mathrm{A}$ is usually obtained from the diet (Novák et al., 2008; Harrison et al., 2012). However, once the vitamin A deficiency occurs, many biological functions within the body will be affected or destroyed. For example, in chickens, lack of vitamin A will affect the egg production, egg quality, production and immune response (Lin et al., 2002; Abdalla et al., 2009; Xiao et al., 2011). In rats, the case of vitamin A deficiency has been reported to lead to congenital malformation in embryos (Warkany et al., 1948; Li et al., 2010).

The hydrophobic molecular structure of vitamin A and its biological derivatives (the retinoids) means that they must be chaperoned both intracellularly and extracellularly by retinoid binding proteins (Newcomer, 1995). Serum retinol-binding protein and cellular retinol-binding protein (CRBPs) respectively is the extracellular and intracellular 
retinol binding protein (Guo et al., 2004). At present, four types of CRBPs (CRBP1, CRBP2, CRBP3, and CRBP4) have been reported. They are highly conserved among mammals (Ong, 1994; Zhang et al., 2012), but have distinct tissue distributions. $C R B P 1$ and $C R B P 4$ are widely distributed throughout the body; meanwhile, $C R B P 1$ is expressed at high levels in the liver, testes, eye and kidney (Piantedosi et al., 2005). CRBP2 is expressed only in the small intestine (Yamaguchi et al., 2009), whereas CRBP3 is restricted to the heart, adipose tissue and skeletal muscle (Caprioli et al., 2004). Of these four, CRBPl is thought to be essential for vitamin A metabolism and synthesis of retinoic acid (Kuppumbatti et al., 2000; Noy, 2000). Although these members of CRBPs have a different expression features, they all affect the activity of enzymes involved in retinoid metabolism (Napoli, 1993). In past studies, some researchers found that excess or deficiency in retinol were associated with egg laying, egg size, embryo survival and hatchability (Thompson, 1969; Boily et al., 1994). In addition, Xiao et al. (2011) and Yin et al. (2013) reported that the variation of $C R B P 2$ and $C R B P 4$ had significant effects on egg production traits. Therefore, the intracellular retinol binding protein, $C R B P 1$ and $C R B P 3$ may play important role in transport, metabolism and homeostasis of retinol. This makes CRBP1 and CRBP3 as good candidate genes for enhancing reproductive traits in chickens. Therefore, to prove this hypothesis, the objective of the current study was to characterize polymorphisms in the partial exons and introns of the CRBPI and CRBP3 gene, and determine their association with laying performance traits in Erlang mountainous chickens.

\section{MATERIAL AND METHODS}

\section{Animals and DNA preparation}

Two lines of SD02 (Shandi chicken) $(\mathrm{n}=188)$ and SD03 $(n=161)$ were enrolled in this study. These chickens are same as used in Xiao's research (Xiao et al., 2011). SD02 and SD03 are new strains that all have the blood of Erlang mountainous chickens (Erlang mountainous chicken, an indigenous chicken breed distributed in Tianquan of Sichuan province, widely adaptable, and have delicious and nutritious meat) and all were developed on an experimental farm for poultry breeding at the Sichuan Agricultural University (Ya'an, China). Meanwhile, there are differences in the specifics of these two strains. SD02 has yellow partridge plumage, blue shanks, white skin and heavy body weight, while SD03 has normal body weight. During the growth period, all birds had free access to food and water ad libitum under the same temperature and lighting conditions.

Six traits were measured and recorded: the age at first egg (AFE), highest continuous egg days (HCD), body weight at first egg (BWFE), weight at first egg (WFE), total number of eggs with 300 ages (EN), and average egg-laying interval (AEI). Approximate $3 \mathrm{~mL}$ blood per chicken was obtained from the wing vein and kept in a vacuum tube containing anticoagulant acid citrate dextrose (ACD). All samples were delivered to the laboratory in an ice box. The genomic DNA was extracted using a standard phenolchloroform method. The DNA samples were dissolved in TE buffer and were stored at -20 until used.

\section{PCR amplifications}

The primers were designed on the basis of DNA sequence of the CRBPI (Accession no. NC_006096.2) and the CRBP3 (Accession no. NC_006088.2) using the oligo nucleotide design tool Primer 5.0 software (Table 1). Primer synthesis was completed by Shanghai Yingjun Biotechnology Co. Ltd. (Shanghai, China). PCR reactions were performed using the Gene Amp PCR System 9700 (Bio-Rad, Hercules, CA, USA) thermal cycler in a final volume of $10 \mu \mathrm{L}$ reaction containing 10 to $100 \mathrm{ng}$ genomic DNA, $5 \mu \mathrm{L} 2 \times$ Taq PCR MasterMix (including $\mathrm{Mg}^{2+}$, dNTPs, Taq DNA polymerase; Beijing TIAN WEI Biology

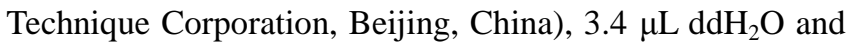
$0.4 \mu \mathrm{L}$ of each primer $(10 \mathrm{pmol} / \mu \mathrm{L})$. The cycling protocol was 4 min at $94^{\circ} \mathrm{C}, 35$ cycles of denaturing at $94^{\circ} \mathrm{C}$ for $30 \mathrm{~s}$, annealing at $\mathrm{X}^{\circ} \mathrm{C}$ (Table 1) for $30 \mathrm{~s}$, extending at $72^{\circ} \mathrm{C}$ for 1 min, with a final extension at $72^{\circ} \mathrm{C}$ for $8 \mathrm{~min}$. The PCR products were characterized in $1 \%$ agarose gel electrophoresis.

\section{Single strand conformation polymorphism and DNA sequencing}

Genetic variants in the $C R B P 1$ and $C R B P 3$ genomic sequence were analyzed by using the PCR-SSCP (single strand conformation polymorphism) method. Each PCR product was diluted in denaturing solution $(95 \%$ formamide deionized, $0.05 \%$ of bromophinol blue, $0.25 \%$ xylene cyanole and $10 \%$ glycerol) and was denatured at $99^{\circ} \mathrm{C}$ for $10 \mathrm{~min}$, then quickly chilled on ice for $5 \mathrm{~min}$. Three microliters of mixture was resolved on $12 \%$ polyacrylamide gel (polyacrylamide:bisacrylamide $=39: 1$ ) using $1 \times \mathrm{TBE}$ buffer and run for 9 to $14 \mathrm{~h}$ at 130 to 150 voltage. The gel was washed in $10 \%$ ethanol for $10 \mathrm{~min}$, then in deionized water for $1 \mathrm{~min}$, followed by an incubation for $10 \mathrm{~min}$ in $0.1 \%$ silver nitrate, and ended with an incubation in $1.5 \%$ sodium hydroxide, $0.01 \%$ sodium borohydride, and $0.4 \%$ (v/v) formaldehyde for $10 \mathrm{~min}$. The bands on the gel were visualized by gel imaging system. After the polymorphisms were detected, each of the DNA bands on the Single strand conformation polymorphism (SSCP) gel was extracted and the PCR products of the different electrophoresis patterns were sent for sequencing in both directions (repeated three times) in an ABI 377 DNA analyzer Applied Biosystems 
Table 1. Detailed information of the primers used for the single nucleotide polymorphism scanning of $C R B P 1$ gene and $C R B P 3$ gene

\begin{tabular}{|c|c|c|c|c|c|}
\hline \multirow{2}{*}{$\begin{array}{l}\text { Gene name } \\
\text { CRBP1 }\end{array}$} & \multicolumn{2}{|c|}{ Primer } & \multirow{2}{*}{$\frac{\text { Sequences }\left(5^{\prime}-3^{\prime}\right)}{\text { ACAATTACCTGAAGTAGGGA }}$} & \multirow{2}{*}{$\begin{array}{c}\begin{array}{c}\text { Annealing } \\
\text { temperature }\left({ }^{\circ} \mathrm{C}\right)\end{array} \\
47.6\end{array}$} & \multirow{2}{*}{$\begin{array}{r}\begin{array}{r}\text { Fragment } \\
\text { length (bp) }\end{array} \\
189\end{array}$} \\
\hline & Exon1 & $\mathrm{F}$ & & & \\
\hline & & $\mathrm{R}$ & ACAAAAATGCTTTATGACCAT & & \\
\hline & Exon2 & $\mathrm{F}$ & AAGCTCTTTTGGTGGTAGATG & 45.2 & 234 \\
\hline & & $\mathrm{R}$ & CATGCATTTGCGATCA & & \\
\hline & Exon3 & $\mathrm{F}$ & ACATGCCCGTTTTCTTAGAC & 58 & 185 \\
\hline & & $\mathrm{R}$ & AGCACTGCATCTAGCCGTTTC & & \\
\hline & Exon4 & $\mathrm{F}$ & ATTATTTTCTCTCCCTAGGAA & 52.5 & 255 \\
\hline & & $\mathrm{R}$ & GGGGTTTTATTTGCAATTAT & & \\
\hline & Intron 1 & $\mathrm{~F}$ & ATGGTGATGTACTTGATGCAG & 51 & 220 \\
\hline & & $\mathrm{R}$ & TGGGAGAAATGAGGTGAAC & & \\
\hline & Intron 2 & $\mathrm{~F}$ & TGTATTTGTGGCTATTCGTAA & 50 & 307 \\
\hline & & $\mathrm{R}$ & AGCTTTTGAGCACCTGATTGT & & \\
\hline & Intron 3 & $\mathrm{~F}$ & TAAATTTATAGTTGCGGTCAT & 50.7 & 320 \\
\hline & & $\mathrm{R}$ & AGTTCCAGGTGACGGGTGAG & & \\
\hline \multirow[t]{16}{*}{ CRBP3 } & Exon1 & $\mathrm{F}$ & GATGGCGTAATGGCTCTAAAG & 48.5 & 104 \\
\hline & & $\mathrm{R}$ & CATCCCCGTTGAGACTATCA & & \\
\hline & Exon2 & $\mathrm{F}$ & AGGTGCTCTGTCTCGGCTTTA & 48 & 199 \\
\hline & & $\mathrm{R}$ & AATGACCGAAGGGTTGGTTGC & & \\
\hline & Exon3 & $\mathrm{F}$ & GAGCCCCCTGTCCAAAGAGTG & 54 & 245 \\
\hline & & $\mathrm{R}$ & GGCACTTGCGCCCATC & & \\
\hline & Exon4 & $\mathrm{F}$ & ACTGCTTTTGTTGGGTCCACG & 56.9 & 176 \\
\hline & & $\mathrm{R}$ & ACCAGGCAAGCTGCATGGG & & \\
\hline & Exon5 & $\mathrm{F}$ & GCCCTTCCTACCCTCGG & 60.8 & 229 \\
\hline & & $\mathrm{R}$ & CGCTGCCATCGAGTTTGCTTC & & \\
\hline & Intron 2 & $\mathrm{~F}$ & ACTCCTCCCTCGTTCTT & 52.5 & 193 \\
\hline & & $\mathrm{R}$ & CAGGCTCCTCCACTCTT & & \\
\hline & Intron 3 & $\mathrm{~F}$ & GGGATGAACCAGAATG & 51.1 & 213 \\
\hline & & $\mathrm{R}$ & CCTTGGGACTGATGCT & & \\
\hline & Intron 4 & $\mathrm{~F}$ & TTGCCTGGTGGTTGG & 53.2 & 137 \\
\hline & & $\mathrm{R}$ & GCGGCGGATGTTTAT & & \\
\hline
\end{tabular}

and the sequences were determined with DNASTAR software (version 7.1, DNASTAR, Inc., Madison, WI, USA) and blast in NCBI (National Center for Biotechnology Information).

\section{Egg quality}

Egg quality parameters of egg weight, eggshell thickness, eggshell strength and yolk color were measured using 150 eggs at 300 day. Eggshell thickness was measured with a vernier caliper to the nearest $0.01 \mathrm{~mm}$. Egg weight $(\mathrm{Wg})$ was determined with an electronic balance to the nearest $0.001 \mathrm{~g}$. The eggshell strength, yolk color and albumin height $(\mathrm{H})$ was measured using an egg quality measuring tester (EMT 5200, Robotmation Co. Ltd., Tokyo, Japan). Then, the egg shape index was calculated as egg diameter divided by an egg length. Haugh unit was determined using the following equation:

$$
\text { Haugh unit }=100 \times \log \left(\mathrm{H}-1.7 \times \mathrm{Wg}^{0.37}+7.57\right)
$$

\section{Statistical analyses}

Genotypic and allelic frequencies and Hardy-Weinberg equilibrium were directly calculated. Population genetic index such as polymorphism information content (PIC) was performed by PopGene software (Version 1.3.1, University of Alberta, Edmonton, Canada) (Yeh et al., 1999). Sequence analysis was performed with DNASTAR software (version 7.1).

Haplotypes of the $C R B P 3$ gene were obtained based on the identified SNPs in 349 chicken samples using the PHASE 2.0 software (University of Chicago, Chicago, IL, USA) (Stephens et al., 2001).

The association analyses between the single marker genotypes and laying performance traits were performed by the PROC general llinear model (GLM) procedure of SAS 6.12 (Statistical Analysis Systems Institute Inc., Cary, NC, USA). The model is as follows:

$$
Y_{i j}=\mu+G_{i}+S_{j}+(G S)_{i j}+e_{i j}
$$


where $Y_{i j}$ was the trait measured in animal, $\mu$ was the population mean, $G_{i}$ was the effect of the genotype for SNP in the CRBPI and CRBP3 gene, $\mathrm{S}_{\mathrm{j}}$ was the effect of sex, $(G S)_{i j}$ was the interaction effect of genotype $i$ by sex $j$, $e_{i j}$ was the residual random effect associated with animal. Data were presented as least square means with associated standard error.

Analyses of the associations between the combined haplotype and laying performance traits were carried out. The model was similar to that of single marker association analysis.

The additive genetic value at each locus was determined using the equation of $(\mathrm{BB}-\mathrm{AA}) / 2$, where $\mathrm{A}$ was the first and $B$ was the second allele of the analyzed markers. Then, the dominance genotypic value for each locus was equal to the difference between the mean of the heterozygotes and the midpoint of the two homozygotes $(\mathrm{AB}-[\mathrm{AA}+\mathrm{BB}] / 2)$.

\section{RESULTS}

Genotype and allele frequencies in chicken populations

In the present study, we first used the PCR-SSCP method to check if there were different bands of PCR product for each primer, and then applied the direct sequencing method to find the possible variations in the different bands of the product. In brief, combining different bands on the SSCP gels (see Materials and Methods section) and sequencing, we detected one SNP in the $C R B P 1$ gene and two SNPs in the CRBP3 gene. We named these polymorphisms relative to their respective positions on sequences of chicken CRBP1 and CRBP3 genes (GenBank accession number NC_006096.2 and NC_006088.2, respectively). The locations of these SNPs are as follows: for CRBP1 gene, one in intron 3 (g.14604G $>\mathrm{T})$; for CRBP3 gene, one in intron 2 (g.934C>G) and one in intron 3 (g.1324A>G).

The strains effect was not significant; therefore, the data from the two varieties of Erlang mountainous chicken were pooled and analyzed together. The results of the genotypes and alleles of the identified SNPs in the CRBPI and CRBP3 genes are shown in Table 2. For CRBPI gene, the allele $\mathrm{G}$ was the dominant allele and presented the highest allele frequencies in Erlang mountainous chicken populations (average $=54.17 \%$ ). The PIC was 0.3730. The overall observed genotypic frequencies deviated from the HardyWeinberg equilibrium $\left(\mathrm{X}^{2}=16.84, \mathrm{p}<0.05\right)$. For $C R B P 3$ gene, considering the first polymorphic site, allele g.934G was the most frequent in the chickens we analyzed $(64.72 \%)$. The most frequent genotype was g.934GG (48.78\%), and the least frequent was g.934CC (19.34\%). The PIC was 0.3521 . The overall observed genotypic frequencies deviated from Hardy-Weinberg equilibrium $\left(\mathrm{X}^{2}\right.$ $=20.96, \mathrm{p}<0.05)$. Similar with g.934C $>\mathrm{T}$, the second SNP showed a higher frequency of the g.1324G allele (62.35\%). The g.1324AG genotype was the most frequent $(48.25 \%)$, and the g.1324AA genotype was the least $(13.53 \%$; PIC = $0.3587)$. The overall observed genotypic frequencies were in Hardy-Weinberg equilibrium $\left(\mathrm{X}^{2}=1.20, \mathrm{p}>0.05\right)$.

\section{Association with laying performance traits and egg quality traits}

The results of the GLM analysis of association between the CRBPI and CRBP3 gene polymorphisms and laying performance traits are summarized in Table 3. As shown in Table 3, for CRBP1 gene, the DNA variation at locus $\mathrm{g}$. $14604 \mathrm{G}>\mathrm{T}$ SNP revealed a highly significant association with AFE, BWFE, WFE and EN ( $<<0.05)$. The chicken of genotype "TT" had lower AFE, BWFE, WFE, and EN than those of genotype "GG" and "GT".

For CRBP3 gene, the SNP at g.934C $>\mathrm{G}$ was significantly associated with AFE $(\mathrm{p}<0.05)$ (Table 3$)$. The chicken of genotype "CC" had the lowest AFE. Meanwhile, the polymorphism g.1324A $>\mathrm{G}$ showed that the AFE of chickens with the AA genotype was significantly lower than those with the AG and GG genotypes, respectively ( $\mathrm{p}<0.05)$. The BWFE values of chicken with the AG genotype were significantly lower than those with the AA and GG genotypes, respectively $(\mathrm{p}<0.05)$. No significant difference was detected for other laying performance traits.

However, no significant difference was detected for egg quality traits in either SNP of $C R B P 3$ gene; meanwhile, for $C R B P 1$ gene, the genotypes were only significantly associated $(\mathrm{p}<0.05)$ with egg-shape index (data not shown).

\section{Association of diplotypes with chicken laying performance and egg quality traits \\ Since there were two SNPs in the CRBP3 gene, the potential effect of the haplotypes g.934C $>\mathrm{G}$ and}

Table 2. Genotypic and allelic frequencies of single nucleotide polymorphisms of $C R B P 1$ and $C R B P 3$ gene

\begin{tabular}{|c|c|c|c|c|c|c|c|c|}
\hline \multirow{2}{*}{ Gene } & \multirow{2}{*}{ SNP } & \multicolumn{2}{|c|}{ Gene frequency } & \multicolumn{3}{|c|}{ Genotype frequency } & \multirow{2}{*}{$X^{2}$} & \multirow{2}{*}{ PIC } \\
\hline & & $\mathrm{G}$ & $\mathrm{T}$ & GG & GT & TT & & \\
\hline$\overline{C R B P 1}$ & g.14604G>T & 0.5417 & 0.4583 & 0.3313 & 0.4209 & 0.2478 & $16.84(\mathrm{p}<0.05)$ & 0.3730 \\
\hline \multirow[t]{4}{*}{$C R B P 3$} & g. $934 C>G$ & $\mathrm{C}$ & G & $\mathrm{CC}$ & $\mathrm{CG}$ & GG & $20.96(\mathrm{p}<0.05)$ & 0.3521 \\
\hline & & 0.3528 & 0.6472 & 0.1934 & 0.3188 & 0.4878 & & \\
\hline & g. $1324 \mathrm{~A}>\mathrm{G}$ & A & $\mathrm{G}$ & AA & $A G$ & GG & $1.20(\mathrm{p}>0.05)$ & 0.3087 \\
\hline & & 0.3765 & 0.6235 & 0.1353 & 0.4825 & 0.3822 & & \\
\hline
\end{tabular}

SNP, single nucleotide polymorphism; PIC, polymorphism information content. 
Table 3. Association of the SNP of $C R B P 1$ and $C R B P 3$ gene and laying performance traits

\begin{tabular}{|c|c|c|c|c|c|}
\hline \multirow[b]{2}{*}{ Trait } & \multicolumn{3}{|c|}{ Genotype (N) } & \multicolumn{2}{|c|}{ Effect } \\
\hline & \multicolumn{2}{|r|}{-- $C R B P 1=$} & TT (51) & Additive & Dominance \\
\hline $\operatorname{AFE}(d)$ & $176.15^{\mathrm{A}} \pm 10.07$ & $177.91^{\mathrm{A}} \pm 10.68$ & $162.33^{\mathrm{B}} \pm 8.19$ & -6.91 & 8.67 \\
\hline BWFE (g) & $1,897.54^{\mathrm{A}} \pm 246.24$ & $1,868.41^{\mathrm{A}} \pm 251.01$ & $2,039.71^{\mathrm{B}} \pm 236.40$ & 71.09 & -100.22 \\
\hline WFE (g) & $40.29^{\mathrm{A}} \pm 5.93$ & $41.18^{\mathrm{A}} \pm 6.23$ & $36.74^{\mathrm{B}} \pm 5.00$ & -1.77 & 2.67 \\
\hline EN (egg) & $78.16^{\mathrm{A}} \pm 17.30$ & $78.70^{\mathrm{A}} \pm 17.80$ & $91.67^{\mathrm{B}} \pm 15.84$ & 6.76 & -6.21 \\
\hline $\operatorname{HCD}(\mathrm{d})$ & $7.35 \pm 3.51$ & $7.89 \pm 4.56$ & $8.43 \pm 4.91$ & 0.54 & 0.00 \\
\hline AEI (d) & $1.70 \pm 0.72$ & $1.69 \pm 0.96$ & $1.46 \pm 0.54$ & -0.12 & 0.11 \\
\hline Trait & CC (67) & $\begin{array}{c}C R B P 3 \\
C G(113)\end{array}$ & GG (169) & & \\
\hline AFE (d) & $169.25^{\mathrm{A}} \pm 11.79$ & $174.50^{\mathrm{Ba}} \pm 10.80$ & $177.52^{\mathrm{Bb}} \pm 10.81$ & 4.13 & 1.12 \\
\hline BWFE (g) & $1,954.18 \pm 262.39$ & $1,914.96 \pm 258.90$ & $1,878.08 \pm 243.17$ & -38.05 & -1.17 \\
\hline WFE (g) & $39.78 \pm 6.00$ & $39.79 \pm 5.92$ & $40.61 \pm 6.29$ & 0.42 & -0.41 \\
\hline EN (egg) & $84.07 \pm 20.13$ & $81.02 \pm 18.01$ & $78.50 \pm 16.73$ & -2.78 & -0.26 \\
\hline $\operatorname{HCD}(\mathrm{d})$ & $8.43 \pm 5.18$ & $7.88 \pm 4.64$ & $7.41 \pm 3.50$ & -0.51 & -0.04 \\
\hline \multirow[t]{2}{*}{$\mathrm{AEI}(\mathrm{d})$} & $1.64 \pm 0.71$ & $1.69 \pm 1.04$ & $1.66 \pm 0.70$ & 0.01 & 0.04 \\
\hline & $\mathrm{AA}(48)$ & AG (168) & GG (133) & & \\
\hline AFE (d) & $169.15^{\mathrm{A}} \pm 11.88$ & $175.35^{\mathrm{B}} \pm 12.98$ & $176.56^{\mathrm{B}} \pm 8.00$ & 3.71 & 2.49 \\
\hline BWFE (g) & $1,997.29^{\mathrm{A}} \pm 259.87$ & $1,862.68^{\mathrm{Ba}} \pm 254.99$ & $1,924.17^{\mathrm{b}} \pm 238.20$ & -36.56 & -98.05 \\
\hline WFE (g) & $39.54 \pm 4.72$ & $39.65 \pm 6.11$ & $41.09 \pm 6.49$ & 0.78 & -0.67 \\
\hline EN (egg) & $83.35 \pm 17.27$ & $80.28 \pm 19.79$ & $79.44 \pm 15.49$ & -1.96 & -1.12 \\
\hline $\mathrm{HCD}(\mathrm{d})$ & $7.19 \pm 3.62$ & $7.95 \pm 4.58$ & $7.73 \pm 4.03$ & 0.27 & 0.49 \\
\hline AEI (d) & $1.61 \pm 0.72$ & $1.68 \pm 0.86$ & $1.65 \pm 0.81$ & 0.02 & 0.05 \\
\hline
\end{tabular}

$\mathrm{N}$, number of individuals; AFE, age at first egg; BWFE, the body weight at first egg; WFE, the weight at first egg; EN, the total number of eggs with 300 age; HCD, the highest continuous egg days; AEI, average egg-laying interval.

Values are presented by the least squares means \pm standard error. Values marked with different superscript differ significantly $(\mathrm{p}<0.05$ ).

g.1324A $>\mathrm{G}$ on laying performance and egg quality traits was analyzed. Four possible haplotypes were discerned: haplotype $1=\mathrm{C}-\mathrm{G}$ with a frequency of $20.31 \%$, haplotype $2=\mathrm{C}-\mathrm{A}$ with a frequency of $15.07 \%$, haplotype $3=\mathrm{G}-\mathrm{G}$ with a frequency of $41.87 \%$, and haplotype $4=\mathrm{G}-\mathrm{A}$ with a frequency of $22.75 \%$. The mixed model analysis indicated that there were significant associations between the haplotypes and partial laying performance traits (Table 4).
Haplotypes were associated with BWFE $(p<0.05)$ and highly associated with AFE $(p<0.01)$.There was no significant association between the haplotypes and other traits. Significant and suggestively dominant effect of the diplotype $\mathrm{H} 2 \mathrm{H} 2$ was observed for AFE, BWFE, EN, and AEI, the diplotype $\mathrm{H} 3 \mathrm{H} 3$ had higher WFE, and the diplotype $\mathrm{H} 1 \mathrm{H} 2$ had higher HCD. Notablely, diplotype H3H4 had a negative effect on AFE and BWFE, H1H1 had

Table 4. Associations of diplotypes of $C R B P 3$ gene with laying performance traits

\begin{tabular}{|c|c|c|c|c|c|c|c|}
\hline \multirow{2}{*}{ Diplotypes } & \multirow{2}{*}{$\mathrm{N}$} & \multicolumn{6}{|c|}{ Traits } \\
\hline & & AFE** & BWFE * & WFE & EN & HCE & AEI \\
\hline H1H1 & 23 & $174.78 \pm 7.85$ & $1,929.78 \pm 258.00$ & $39.24 \pm 4.81$ & $76.30 \pm 15.05$ & $7.17 \pm 3.86$ & $1.77 \pm 0.67$ \\
\hline $\mathrm{H} 1 \mathrm{H} 2$ & 32 & $167.59 \pm 13.49$ & $1,916.56 \pm 257.87$ & $39.45 \pm 6.92$ & $87.44 \pm 23.59$ & $10.03 \pm 6.27$ & $1.64 \pm 0.81$ \\
\hline $\mathrm{H} 1 \mathrm{H} 3$ & 35 & $175.20 \pm 8.06$ & $1,960.29 \pm 227.90$ & $40.54 \pm 6.85$ & $81.54 \pm 18.41$ & $7.71 \pm 3.54$ & $1.68 \pm 1.20$ \\
\hline $\mathrm{H} 2 \mathrm{H} 2$ & 12 & $163.08 \pm 9.14$ & $2,101.25 \pm 252.21$ & $41.71 \pm 5.43$ & $90.00 \pm 14.56$ & $6.58 \pm 2.50$ & $1.36 \pm 0.39$ \\
\hline $\mathrm{H} 2 \mathrm{H} 3$ & 64 & $176.09 \pm 11.90$ & $1,867.03 \pm 267.06$ & $39.50 \pm 5.70$ & $80.14 \pm 19.07$ & $7.97 \pm 5.05$ & $1.72 \pm 1.04$ \\
\hline $\mathrm{H} 2 \mathrm{H} 4$ & 14 & $165.50 \pm 6.94$ & $2,020.71 \pm 259.12$ & $39.26 \pm 4.40$ & $83.71 \pm 11.63$ & $7.93 \pm 5.34$ & $1.62 \pm 0.48$ \\
\hline $\mathrm{H} 3 \mathrm{H} 3$ & 75 & $177.73 \pm 7.93$ & $1,905.60 \pm 237.87$ & $41.92 \pm 6.69$ & $79.43 \pm 14.14$ & $7.91 \pm 4.32$ & $1.60 \pm 0.60$ \\
\hline $\mathrm{H} 3 \mathrm{H} 4$ & 72 & $178.14 \pm 12.47$ & $1,834.86 \pm 241.89$ & $39.88 \pm 6.16$ & $77.22 \pm 17.97$ & $7.01 \pm 2.59$ & $1.66 \pm 0.71$ \\
\hline $\mathrm{H} 4 \mathrm{H} 4$ & 22 & $174.77 \pm 13.39$ & $1,925.68 \pm 253.67$ & $38.53 \pm 4.32$ & $79.50 \pm 20.78$ & $7.05 \pm 2.80$ & $1.75 \pm 0.94$ \\
\hline
\end{tabular}

Single "** means that there is significant different between least mean squares for a certain trait $(\mathrm{p}<0.050)$; Double “**” mean there is great significant different between least mean squares for a certain trait $(\mathrm{p}<0.01)$.

N, number of individuals; AFE, age at first egg; BWFE, the body weight at first egg; WFE, the weight at first egg; EN, the total number of eggs with 300 age; HCE, the highest continuous egg days; AEI, Average egg-laying interval. 
the highest reducing effect on $\mathrm{EN}$, and $\mathrm{H} 4 \mathrm{H} 4$ had the highest reducing effect on WFE. However, there were no significant association between the haplotypes and all egg quality traits (data not shown).

\section{DISCUSSION}

Vitamin A (retinol) is a fat-soluble vitamin that has received attention with respect to its important role in many physiological functions in poultry. Furthermore, the level of vitamin A can affect egg production, feed intake, egg production rate (Kucuk et al., 2003; Shao et al., 2010) and egg quality. However, due to vitamin A and its metabolites being hydrophobic, they are bound to CRBPs (type 1, 2, 3 and 4) in the cytoplasm (Mezaki et al., 2012). Therefore, in this study, SNP analysis of two different types of cellular retinol-binding protein, $C R B P 1$ and $C R B P 3$, was performed to assess whether variation in their sequence could affect the egg production and egg quality in Erlang mountainous chicken.

This study, which was designed as the first step in detecting genetic markers for egg production and egg quality of chicken, uncovered variation in the chicken $C R B P 1$ and CRBP3 gene sequence that has not been reported in previous research and may provide information for a future marker assisted selection (MAS) program. In this study, we detected one SNP (g. 14604G $>$ T) in CRBPl gene and two SNPs (g.934C $>\mathrm{G}$ and g.1324A $>\mathrm{G}$ ) in $C R B P 3$ gene. Association analysis revealed that the g. $14604 \mathrm{G}>\mathrm{T}$ of $C R B P 1$ gene was significantly associated with AFE, BWFE, WFE, and EN, but not with other traits. Moreover, the g.934C $>\mathrm{G}$ and g.1324A $>\mathrm{G}$ of $C R B P 3$ gene were all significantly associated with AFE, meanwhile, the BWFE values of $\mathrm{g} .1324 \mathrm{~A}>\mathrm{G}$ in $C R B P 3$ gene with the $\mathrm{AG}$ genotype were significantly lower than those with the AA and GG genotypes. Several studies addressed the effect of the vitamin A on laying rate and egg production. Since $C R B P 1$ and $C R B P 3$ are members of the CRBPs protein family, the mutations might affect the vitamin A metabolism and transportation, which may influence cell proliferation, differentiation and development. We believe that this is reason for the $C R B P 1$ and $C R B P 3$ gene mutations being associated with partial egg production traits.

On the other hand, for egg quality, no significant difference was detected for egg qualities (egg-shape index, average egg weight, eggshell strength, eggshell thickness, haugh unit, yolk color and the percentage of yolk) in g.934C $>\mathrm{G}$ and g. $1324 \mathrm{~A}>\mathrm{G}$ of the $C R B P 3$ gene in our study. This result is in agreement with those reported by Hao et al. (2000) and Wang (2008). While, Shao et al. (2010) and Ren et al. (2007) reported that vitamin A has a significant influence on average egg weight. Moreover, the genotype of g. $14604 \mathrm{G}>\mathrm{T}$ in the $C R B P 1$ gene was associated with egg- shape index, the opposite result was found in Wang's report (Wang, 2008). In addition, these three SNPs of CRBPl and $C R B P 3$ which were obtained from intron 2 and intron 3 were synonymous and caused no change in amino acids; the mutation still had an effect on partial egg production traits. So, we think that there are two possible explanations could be offered. One is the mutations could affect $C R B P 1$ and $C R B P 3$ function by altering the mRNA stability (Capon et al., 2004). The other is that the nucleotide substitution or the frame-shift mutation of the genetic mutation may be able to change the amino sequence of the target gene, or be terminated without producing peptide synthesis of complete peptide chains.

However, some research reported that associations of haplotypes with important economic traits were more accurate than those of single SNPs (Daly et al., 2001; Zhang et al., 2008). This result implied that there was an interaction between different SNPs, and that the haplotypes generally provided more information than SNPs (Stephens et al., 2001). Therefore, haplotype play an important role in association studies. We reconstructed haplotypes based on two common CRBP3 gene SNPs and discerned an association between the diplotypes and egg production traits Particularly, $\mathrm{H} 2 \mathrm{H} 2$ diplotype was found to contribute more to AFE, BWFE, EN, and AEI than the other diplotypes.

In general, this study is the first to show an association between a DNA variation in the $C R B P 1$ and $C R B P 3$ genes and egg production and egg quality in chicken. Associations were found for one $C R B P 1 \mathrm{SNP}$ and two CRBP3 SNPs with several egg production traits but they had no effect on egg quality. To contribute to genetic improvement of egg production and egg quality of chicken, future studies with larger sample size and with chicken with phenotypic information are necessary to better understand the regulatory mechanisms of polymorphism and parent-oforigin effect on gene expression of $C R B P 1$ and $C R B P 3$.

\section{ACKNOWLEDGMENTS}

The authors thank Jiangyuan-Li and Yao Zhang for collecting samples and data. The authors are also indebted to XiaoLi-Shao for her technical assistance during experiments. This work was supported by the breeding research project of Sichuan Province (No. 2011NZ0099-7), the support program of Sichuan Province (No. 2011NZ0073) and the major projects of the department of agriculture (No. CARS-41).

\section{REFERENCES}

Abdalla, A. A., N. A. Mosaad, and N. Y. Elnagdy. 2009. Effect of vitamin A supplementation on the performance and immune response of bandarah chicken. Egyptian Poult. Sci. J. 29:221239. 
Boily, M. H., L. Champoux, D. H. Bourbonnais, J. L. Granges, J. Rodrigue, and P. A. Spear. 1994. $\beta$-Carotene and retinoids in eggs of Great Blue Herons (Ardea herodias) in relation to St Lawrence River contamination. Ecotoxicology 3:271-286.

Caprioli, A., H. Zhu, and T. N. Sato. 2004. CRBP-III: lacZ expression pattern reveals a novel heterogeneity of vascular endothelial cells. Genesis 40:139-145.

Capon, F., M. H. Allen, M. Ameen, A. D. Burden, D. Tillman, J. N. Barker, and R. C. Trembath. 2004. A synonymous SNP of the corneodesmosin gene leads to increased mRNA stability and demonstrates association with psoriasis across diverse ethnic groups. Hum. Mol. Genet. 13:2361-2368.

Daly, M. J., J. D. Rioux, S. F. Schaffner, T. J. Hudson, and E. S. Lander. 2001. High-resolution haplotype structure in the human genome. Nat. Genet. 29:229-232.

Eskild, W. and V. Hansson. 1994. Vitamin A functions in the reproductive organs. In: Vitamin A in Health and Disease (Ed. R. Blomhoff ). Marcel Dekker, New York, USA. pp. 531-559.

Guo, X. H., M. X. Chu, and Z. X. Zhou. 2004. Progress on retinolbinding protein and their genes. Hereditas 26:257-262.

Hao, Z. L., Z. G. Jia, and G. H. Xiang. 2000. Effect of supplemental levels of three vitamin levels on egg production in laying hens. Gansu. Anim. Vet. Sci. 30:13-15.

Harrison, E. H. 2012. Mechanisms involved in the intestinal absorption of dietary vitamin A and provitamin A carotenoids. Biochim. Biophys. Acta Mol. Cell Biol. Lipids 1821:70-77.

Hofmann, C. and G. Eichele. 1994. Retinoids in development. In: The Retinoids: Biology, Chemistry, and Medicine (Ed. M. B. Sporn, A. B. Roberts, and D. S. Goodman). Raven Press, New York, USA. pp. 387-441.

Kucuk, O., N. Sahin, and K. Sahin. 2003. Supplemental zinc and vitamin A can alleviate negative effects of heat stress in broiler chickens. Biol. Trace. Elem. Res. 94:225-235.

Li, N., S. S. Sun, D. Wang, P. Yao, X. F. Yang, H. Yan, Y. K. Du, C. J. Ying, and L. G. Liu. 2010. Suppression of retinoic acid receptors may contribute to embryonic skeleton hypoplasia in maternal rats with chronic vitamin A deficiency. J. Nutr. Biochem. 21:710-716.

Lin, H., L. F. Wang, J. L. Song, Y. M. Xie, and Q. M. Yang. 2002. Effect of dietary supplemental levels of vitamin A on the egg production and immune responses of heat-stressed laying hens. Poult. Sci. 81:458-465.

Linan-Cabello, M. A., J. Paniagua-Michel, and P. M. Hopkins. 2002. Bioactive roles of carotenoids and retinoids in crustaceans. Aquac. Nutr. 8:299-309.

Mezaki, Y., M. Morii, K. Yoshikawa, N. Yamaguchi, M. Miura, K. Imai, H. Yoshino, and H. Senoo. 2012. Characterization of a cellular retinol-binding protein from lamprey, lethenteron japonicum. Com. Biochem. Physiol. B, Biochem. Mol. Biol. 161:233-239.

Napoli, J. L. 1993. Biosynthesis and metabolism of retinoic acid: Roles of CRBP and CRABP in retinoic acid: roles of CRBP and CRABP in retinoic acid homeostasis. J. Nutr. 123 (Suppl.):362-366.

Newcomer, M. E. 1995. Retinoid-binding proteins: Structural determinants important for function. FASEB. J. 9:229-239.
Novák, J., Beníšek, and M. Hilscherová. 2008. Disruption of retinoid transport, metabolism and signaling by environmental pollutants. Environ. Int. 34: 898-913.

Noy, N. 2000. Retinoid-binding proteins: Mediators of retinoid action. Biochem. J. 348:481-495.

Ong, D. E. 1994. Cellular transport and metabolism of vitamin A: Role of the cellular retinoid-binding proteins. Nutr. Rev. 52: S24-S31.

Rando, R. R. 1994. Retinoid isomerization reactions in the visual system. In: Vitamin A in Health and Disease (Ed. R. Blomhoff). Marcel Dekker, New York, USA. pp. 503-529.

Reichrath, J., B. Lehmann, C. Carlberg, J. Varani, and C. C. Zouboulis. 2007. Vitamins as hormones. Horm. Metab. Res. 39:71-84.

Ren, Z. L., Y. S. Gong, and H. J. Wu. 2007. Study the effect of vitamin $\mathrm{A}, \mathrm{E}$ and $\mathrm{B}$ on the production and partial biochemical criterion of laying hens. Contemp. Anim. Husb. 1:24-26.

Ross, A. C. and U. G. Hammerling. 1994. Retinoids and the immune system. In: The Retinoids: Biology, Chemistry, and Medicine (Ed. M. B. Sporn, A. B. Roberts, and D. S. Goodman). Raven Press, New York, USA. pp. 521-543.

Shao, Y. K., Z. Y. Zhang, and X. G. Shang. 2010. Effect of different level of vitamin A on egg production and egg quality of laying hens. Feed. Ind. 31(8):1-3.

Stephens, J. C., J. A. Schneider, D. A. Tanguay, J. Choi, T. Acharya, S. E. Stanley, R. H. Jiang, C. J. Messer, A. Chew, J. H. Han, J. C. Duan, J. L. Carr, M. S. Lee, B. Koshy, A. M. Kumar, G. Zhang, W. R. Newell, A. Windemuth, C. B. Xu, T. S. Kalbfleisch, S. L. Shaner, K. Arnold, V. Schulz, C. M. Drysdale, K. Nandabalan, R. S. Judson, G. Ruano, and G. F. Vovis. 2001. Haplotype variations and linkage disequilibrium in 313 human genes. Science 293:489-493.

Thompson, J. N. 1969. The role of vitamin A in reproduction. The Fat Soluble Vitamins (Ed. R. A. Morton). University of Wisconsin Press, Madison, WI, USA. 267-281.

Wang, X. J. 2008. Effect of dietary supplemental levels of vitamin $\mathrm{A}$ and vitamin $\mathrm{D}$ on the egg production and eggshell quality of laying hens. Mod. Agr. Sci. Tech. 4:175-178.

Warkany, J., C. Roth, and J. G. Wilson. 1948. Multiple congenital malformations: a consideration of etiologic factors. Pediatrics 1:462-471.

Xiao, L. H., S. Y. Chen, X. L. Zhao, Q. Zhu, and Y. P. Liu. 2011. Association of cellular retinol-binding protein 2 (CRBP2) gene polymorphism with egg production in erlang mountainous chicken. J. Poult. Sci. 48:162-167.

Yamaguchi, N., S. Miyamoto, Y. Ogura, T. Goda, and K. Suruga. 2009. Hepatocyte nuclear factor- alpha regulates human cellular retinol-binding protein type II gene expression in intestinal cells. Am. J. Physiol-Gastr. L. 296:G524-533.

Zhang, Y. R., Y. Q. Zhao, and J. F. Huang. 2012. Retinoid-binding proteins: similar protein architectures bind similar ligands via completely different ways. PlosOne. 7(5): e36772.

Zhang, Z. R., Y. P. Liu, X. Jiang, H. R. Du, and Q. Zhu. 2008. Study on association of single nucleotide polymorphism of CAPN1 gene with muscle fiber and carcass traits in quality chicken populations. J. Anim. Breed. Genet. 125:258-264. 